University of Wollongong

Research Online

Faculty of Engineering and Information

Faculty of Engineering and Information

Sciences - Papers: Part A

Sciences

$1-1-2013$

Unconventional block shear failures of bolted connections in cold-reduced steel sheets

Lip H. Teh

University of Wollongong, Iteh@uow.edu.au

Veysel Yazici

University of Wollongong, veysel@uow.edu.au

Follow this and additional works at: https://ro.uow.edu.au/eispapers

Part of the Engineering Commons, and the Science and Technology Studies Commons

Research Online is the open access institutional repository for the University of Wollongong. For further information contact the UOW Library: research-pubs@uow.edu.au 


\title{
Unconventional block shear failures of bolted connections in cold-reduced steel sheets
}

\author{
Abstract \\ This paper examines the block shear design equation proposed by the first author based on laboratory \\ tests of bolted connection specimens failing in the conventional block shear failure mode. It shows that \\ the explanation regarding the feasible mechanism of block shear failures previously provided by the first \\ author does not necessarily apply to staggered bolted connections, in which the downstream bolts do not \\ have the same edge distance. For staggered bolted connections, a block shear failure may occur through \\ the shear rupture and tensile yielding mechanism for particular configurations, as demonstrated for the \\ first time in this paper. The present laboratory tests included specimens failing in the split block shear \\ failure mode. This paper presents the equations for determining staggered and split block shear \\ capacities. It also cautions against potential misidentifications for the simultaneous shear and tensile \\ ruptures mechanism.

\section{Disciplines} \\ Engineering | Science and Technology Studies

\section{Publication Details} \\ Teh, L. H. \& Yazici, V. (2013). Unconventional block shear failures of bolted connections in cold-reduced \\ steel sheets. Engineering Structures, 56 567-571.
}




\title{
Unconventional Block Shear Failures of Bolted Connections in Cold-Reduced Steel Sheets
}

\author{
Lip H. Teh ${ }^{\mathrm{a}^{*}}$, Veysel Yazici ${ }^{\mathrm{b}}$ \\ ${ }^{a}$ Senior Lecturer, School of Civil, Mining \& Environmental Engineering, University of Wollongong, Wollongong, \\ NSW 2522, Australia. \\ ${ }^{b}$ Research Assistant, School of Civil, Mining \& Environmental Engineering, University of Wollongong, \\ Wollongong, NSW 2522, Australia. \\ *Corresponding author at School of Civil, Mining \& Environmental Engineering, University of Wollongong, \\ Wollongong, NSW 2522, Australia. Tel: +61242213564, fax: +61242213238, e-mail: 1teh@uow.edu.au
}

\section{Introduction}

In a recent paper, Teh \& Clements [1] pointed out that, for an unstaggered bolted connection, there is no aspect ratio at which the shear rupture and tensile yielding mechanism governs the conventional block shear failure mode. The aspect ratio is the ratio between the length of the shear resistance plane and the length of the tensile resistance plane in a "block". Connections with low aspect ratios fail by individual (and simultaneous) shear-out of the bolts, while those with higher aspect ratios fail in block shear by the shear yielding and tensile rupture mechanism. Published experimental tests have found that block shear failures invariably occurred by the shear yielding and tensile rupture mechanism [1-4].

However, the expositions of Teh \& Clements [1] have been based on unstaggered bolting patterns. In a staggered bolted connection, the bolts have different edge distances from the downstream end, so it is not possible for simultaneous shear-out failures to occur under concentric loading. The shear stresses downstream from the leading bolt are greater than those downstream from the other bolt(s), and for certain configurations shear rupture at the leading 
bolt may occur in conjunction with tensile yielding along the inclined net section to form a block shear failure. A laboratory test supporting this assertion will be presented.

In this paper, the equation presented by Teh \& Clements [1], used for determining the block shear capacity of an unstaggered bolted connection, will be combined with that presented by Teh \& Clements [5], used for determining the net section tension capacity of a staggered bolted connection, to form one for determining the block shear capacity of a staggered bolted connection in cold-reduced steel sheets having low material ductility and minimal strain hardening capability. The derived equation will then be verified against laboratory test results.

This paper includes the laboratory test results of bolted connection specimens failing by the split block shear failure, in which there are two critical tensile resistance planes. Such a failure mode is particularly relevant to channel braces bolted at both flanges, which is a common arrangement for the frame braces of a cold-formed steel storage rack. The equation presented by Teh \& Clements [1] will be modified to suit a split block shear failure.

This paper also cautions against possible misidentifications for block shear failures by the simultaneous shear and tensile ruptures mechanism. It points out two phenomena that can lead to such misidentifications. It may be noted that possible misidentification of a block shear failure by the shear yielding and tensile rupture mechanism for a net section fracture has been discussed previously by the authors [6]. There is also continuing research in the area of block shear failures of steel bolted connections as represented by a very recent paper [7]. Block shear failures of welded connections $[8,9]$ are distinct from those of bolted connections, and are outside the scope of this paper. 


\section{Relevant equations}

Teh \& Clements [1] proposed the following equation for determining the conventional block shear capacity $P_{\mathrm{c}}$ of the unstaggered bolted connection in cold-reduced steel sheet shown in Figure 1

$$
P_{c}=0.6 F_{y} A_{a v}+F_{u} A_{n t}(0.9+0.1 \mathrm{~d} / \mathrm{g})
$$

in which $F_{\mathrm{u}}$ is the material tensile strength, $F_{\mathrm{y}}$ is the yield stress, $A_{\mathrm{nt}}$ is the net tensile area and $A_{\mathrm{av}}$ is the active shear area determined from the length of the active shear planes [10], as indicated in the figure. The variable $d$ in Equation (1) denotes the bolt diameter, and $g$ is the connection gage as defined in Figure 1. In the figure, $d_{\mathrm{h}}$ is the bolt hole diameter.

For a staggered bolted connection in cold-reduced steel sheet shown in Figure 2, Teh \& Clements [5] proposed the following equation for determining the net section tension capacity

$$
P_{n s}=F_{u} t\left[W-\max \left(d_{h}, 2 d_{h}-\frac{s^{2}}{4 g+2 d_{h}}\right)\right](0.9+0.1 d / W)
$$

which, for a connection with tension failure along the staggered path, becomes

$$
P_{n s}=F_{u} t\left[W-2 d_{h}+\frac{s^{2}}{4 g+2 d_{h}}\right](0.9+0.1 d / W)
$$

The in-plane shear lag terms shown inside the last brackets of Equations (1) and (2) have been derived by Teh \& Gilbert [11]. The variable $t$ in Equation (2) denotes the sheet thickness, and $s$ is the bolt pitch defined in Figure 2. 
For the staggered bolted connection shown in Figure 2, Equations (1) and (2b) can be combined to determine the staggered block shear capacity

$$
P_{s t}=0.6 F_{y} A_{a v}+F_{u} t\left[g-d_{h}+\frac{s^{2}}{4 g+2 d_{h}}\right](0.9+0.1 d / g)
$$

For certain rectangular connection configurations where the sum of the outer tensile areas is less than the inner tensile area, the "split" block shear failure may occur, as illustrated in Figure 3. Equation (1) becomes

$$
P_{s p}=0.6 F_{y} A_{a v}+F_{u} A_{n t}\left(0.9+0.05 d / e_{2}\right)
$$
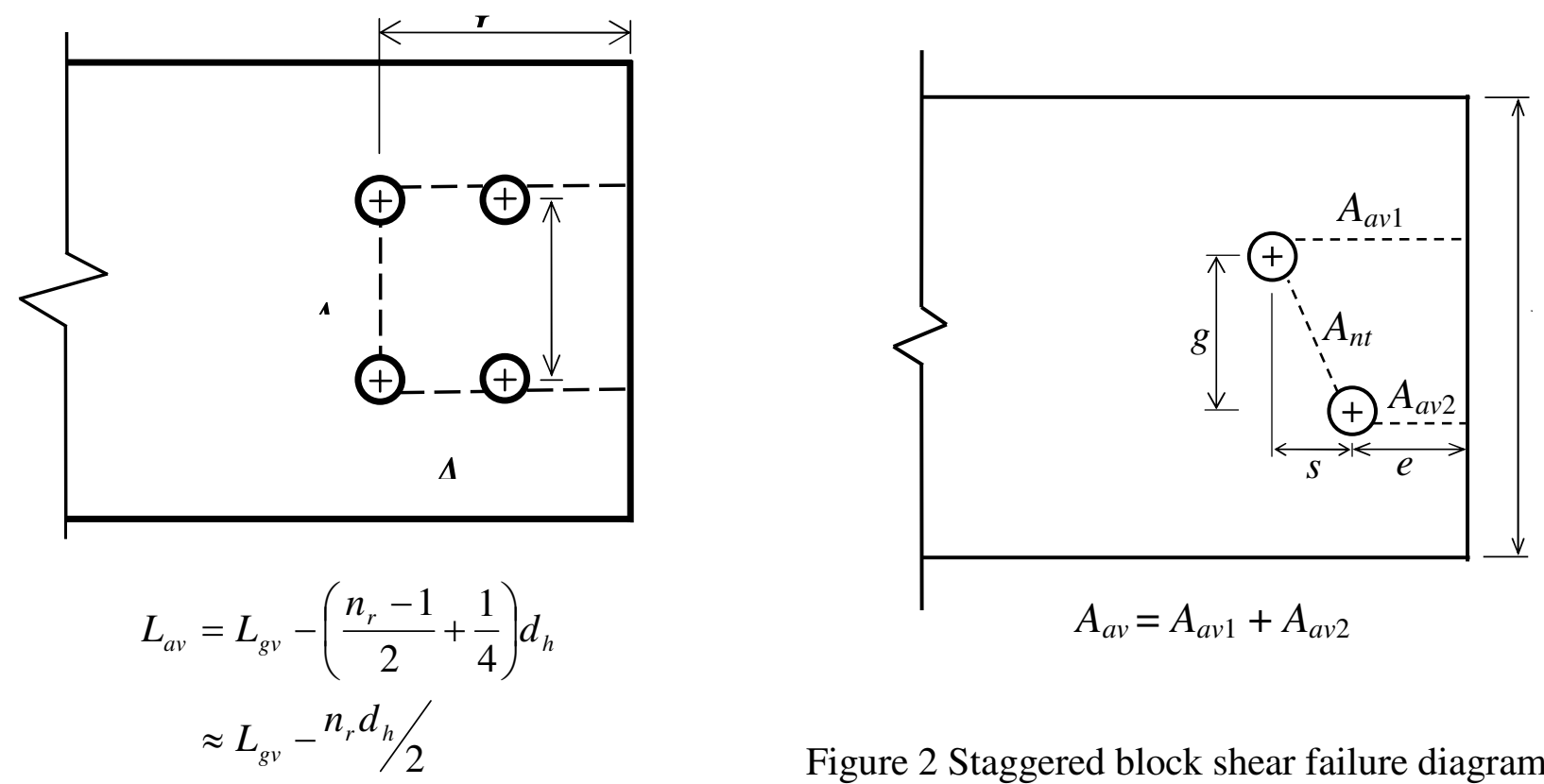

Figure 1 Conventional block shear failure diagram

Figure 2 Staggered block shear failure diagram 


\section{Test materials}

The G450 sheet steel materials used in the laboratory tests, which have a trade name GALVASPAN $^{\circledR}$, were manufactured and supplied by Bluescope Steel Port Kembla Steelworks, Australia. Two nominal thicknesses were used in the present work, being $1.5 \mathrm{~mm}$ and $3.0 \mathrm{~mm}$. The average base metal thicknesses $t_{\text {base, }}$ yield stresses $F_{y}$, tensile strengths $F_{u}$ and elongations at fracture over $15 \mathrm{~mm}, 25 \mathrm{~mm}$ and $50 \mathrm{~mm}$ gauge lengths $\varepsilon_{15}, \varepsilon_{25}$ and $\varepsilon_{50}$, and uniform elongation outside fracture $\varepsilon_{\text {ио }}$ of the steel materials as obtained from six $12.5 \mathrm{~mm}$ wide tension coupons are shown in Table 1 [11]. Tensile loadings of all coupons and bolted connection specimens are in the direction perpendicular to the rolling direction of the G450 sheet steel.

The tensile strengths in the direction perpendicular to the rolling direction of $1.5 \mathrm{~mm}$ and $3.0 \mathrm{~mm}$ G450 sheet steels obtained for the present work, rounded to the nearest $5 \mathrm{MPa}$, are $6 \%$ and $10 \%$ higher than those obtained by Teh \& Hancock [12] in the rolling direction. While Teh \& Hancock [12] did not provide the elongations at fracture, it is believed that the rolling direction is associated with higher ductility. In any case, it can be seen from Table 1 that the present materials have low ductility and relatively insignificant strain hardening capability.

\section{Laboratory tests and discussions}

All specimens were subjected to concentric loading as depicted by Teh \& Clements [1].

In calculating the block shear capacity of a specimen using Equation (3) or (4), the measured values of the geometric dimensions such as the base metal thickness, the bolt hole diameter and the bolt spacing were used. However, for legibility and ease of comparisons across different 
configurations, only the nominal values are shown in the tables following. An empty cell indicates that the data in the above cell applies.

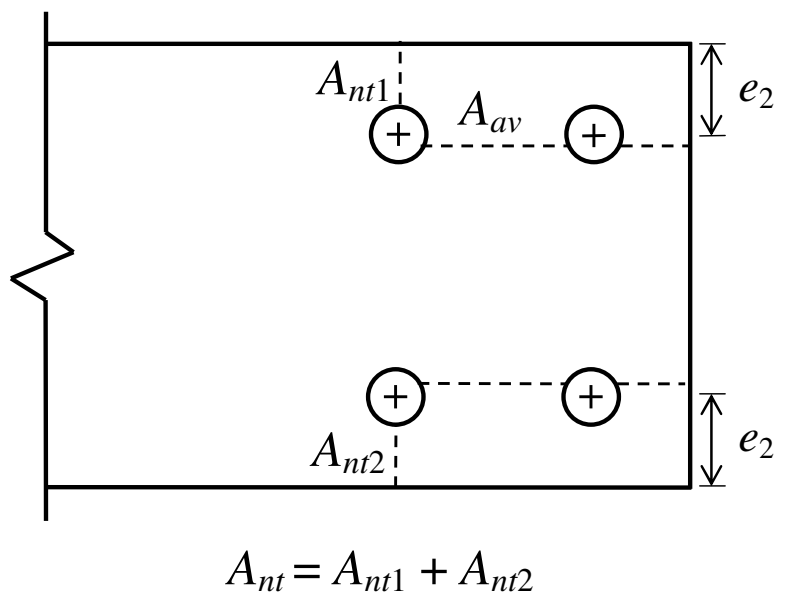

Figure 3 Split block shear failure diagram

\begin{tabular}{|c|c|c|c|c|c|c|}
\hline No. & Label & $\begin{array}{c}g \\
(\mathrm{~mm})\end{array}$ & $\begin{array}{c}s \\
(\mathrm{~mm})\end{array}$ & $\begin{array}{c}e \\
(\mathrm{~mm})\end{array}$ & $\begin{array}{c}P_{\mathrm{t}} \\
(\mathrm{kN})\end{array}$ & $P_{\mathrm{t}} / P_{\mathrm{st}}$ \\
\hline 1 & CT55a & 40 & 30 & 30 & 109.2 & 1.02 \\
\hline 2 & CT55b & & & & 109.2 & 1.00 \\
\hline 3 & СТ56a & & & 25 & 100.8 & 1.04 \\
\hline 4 & CT56b & & & & 98.5 & 1.03 \\
\hline 5 & CT57 & 45 & & 30 & 111.3 & 0.99 \\
\hline 6 & CT58 & & & 25 & 103.9 & 0.99 \\
\hline 7 & CT65 & & 25 & & 103.0 & 1.07 \\
\hline 8 & CT59 & & & 30 & 111.1 & 1.05 \\
\hline 9 & СT60 & 50 & & & 118.4 & 1.04 \\
\hline 10 & CT61 & & 20 & & 112.7 & 1.04 \\
\hline
\end{tabular}

Table 1 Average material properties

\begin{tabular}{ccccccccc}
\hline & $\boldsymbol{t}_{\text {base }}$ & $\boldsymbol{F}_{\mathbf{y}}$ & $\boldsymbol{F}_{\mathbf{u}}$ & $\boldsymbol{F}_{\mathbf{u}} / \boldsymbol{F}_{\mathbf{y}}$ & & $\boldsymbol{\varepsilon}_{\mathbf{2 5}}$ & $\boldsymbol{\varepsilon}_{\mathbf{5 0}}$ & $\boldsymbol{\varepsilon}_{\mathbf{u o}}$ \\
& $(\mathbf{m m})$ & $(\mathbf{M P a})$ & $(\mathbf{M P a})$ & & $(\boldsymbol{\%})$ & $(\boldsymbol{\%})$ & $(\boldsymbol{\%})$ & $(\boldsymbol{\%})$ \\
\hline $1.5 \mathrm{~mm}$ & 1.48 & 605 & 630 & 1.04 & 21.3 & 18.0 & 12.0 & 6.8 \\
\hline $3.0 \mathrm{~mm}$ & 2.95 & 530 & 580 & 1.09 & 29.3 & 22.0 & 15.3 & 8.1 \\
\hline
\end{tabular}


Table 3 Results of split block shear failures

\begin{tabular}{ccccccc}
\hline No & Label & $\begin{array}{c}g \\
(\mathrm{~mm})\end{array}$ & $\begin{array}{c}t \\
(\mathrm{~mm})\end{array}$ & $\begin{array}{c}L_{\mathrm{gv}} \\
(\mathrm{mm})\end{array}$ & $\begin{array}{c}P_{\mathrm{t}} \\
(\mathrm{kN})\end{array}$ & $P_{\mathrm{t}} / P_{\mathrm{sp}}$ \\
\hline 11 & CPD30a & 70 & 1.5 & 50 & 69.4 & 0.96 \\
12 & CPD32 & & 3.0 & & 136.9 & 1.04 \\
13 & CPD46a & 65 & 1.5 & 45 & 75.3 & 1.03 \\
14 & CPD48 & & 3.0 & & 145.6 & 1.12 \\
\hline
\end{tabular}

\subsection{Staggered block shear failure}

Ten specimens were tested in order to investigate the accuracy of Equation (3) in determining the block shear capacities of staggered bolted connections. All of them were composed of $3.0 \mathrm{~mm}$ G450 sheet steel and had two $16 \mathrm{~mm}$ bolts that were staggered. Table 2 lists the relevant geometric dimensions and the ratios of the ultimate test load $P_{\mathrm{t}}$ to the staggered block shear capacity $P_{\text {st }}$ predicted by Equation (3), called the professional factors. The variable $e$ in the table is the edge distance of the leading bolt, defined in Figure 2.

All the specimens in Table 2 failed in block shear by the shear yielding and tensile rupture mechanism, as shown in Figure 4, except for specimen CT58.

Figure 5 shows that specimen CT58 failed in block shear by the shear rupture and tensile yielding mechanism. It was not a shear-out failure since there was necking along the inclined net section, and shear rupture only took place at the perimeter of the block shear region (i.e. on one side of the bolt only). 
It also transpires that, for specimen CT58, swapping the yield stress $F_{\mathrm{y}}$ and the tensile strength $F_{\mathrm{u}}$ in Equation (3) results in the same professional factor $P_{\mathrm{t}} / P_{\text {st }}$ given in Table 2. It may be noted that Cunningham et al. [13] have shown that a mean professional factor close to unity can always be achieved through regression analysis of the concerned data for any mechanism arbitrarily assumed for the block shear failures.

The shear rupture and tensile yielding mechanism was only achieved for specimen CT58 among the eight configurations experimented with. It can be seen from Table 2 that individually varying the edge distance $e$ (CT55 versus CT56), the connection gage $g$ (CT55 versus CT57, CT59 versus CT60), or the bolt pitch s (CT57 versus CT59, CT60 versus CT61) did not change the shear yielding and tensile rupture mechanism. However, changing any one of this variable for CT58 avoided the shear rupture and tensile yielding mechanism (CT56 for the connection gage $g$, CT57 for the edge distance $e$, CT65 for the bolt pitch $s$ ). The reader may refer to Teh \& Clements [1] for an explanation why the shear rupture and tensile yielding mechanism is so rare.

Figure 4(b) could appear to show the simultaneous shear and tensile ruptures mechanism of specimen CT56a. However, the rupture at the downstream edge was due to the normal stresses acting transverse to the direction of loading, not due to the shear stresses. The normal stresses resulted from "in-plane flexure" of the narrow strip in front of the leading bolt [14].

In any case, the block shear capacity of each specimen in Table 2 was determined by Equation (3) with excellent accuracy. 


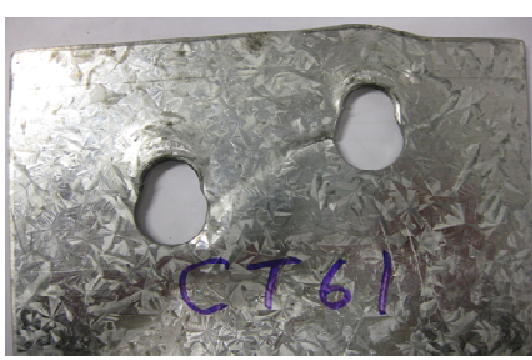

(a)

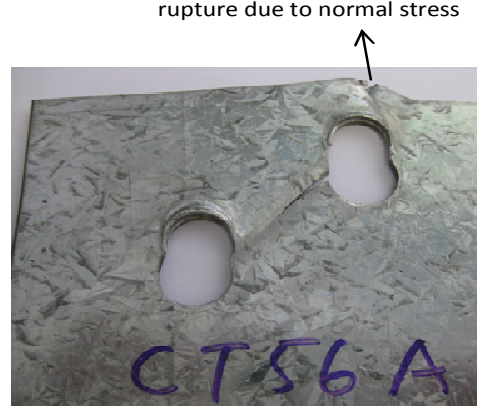

(b)

Figure 4 Shear yielding and tensile rupture mechanism

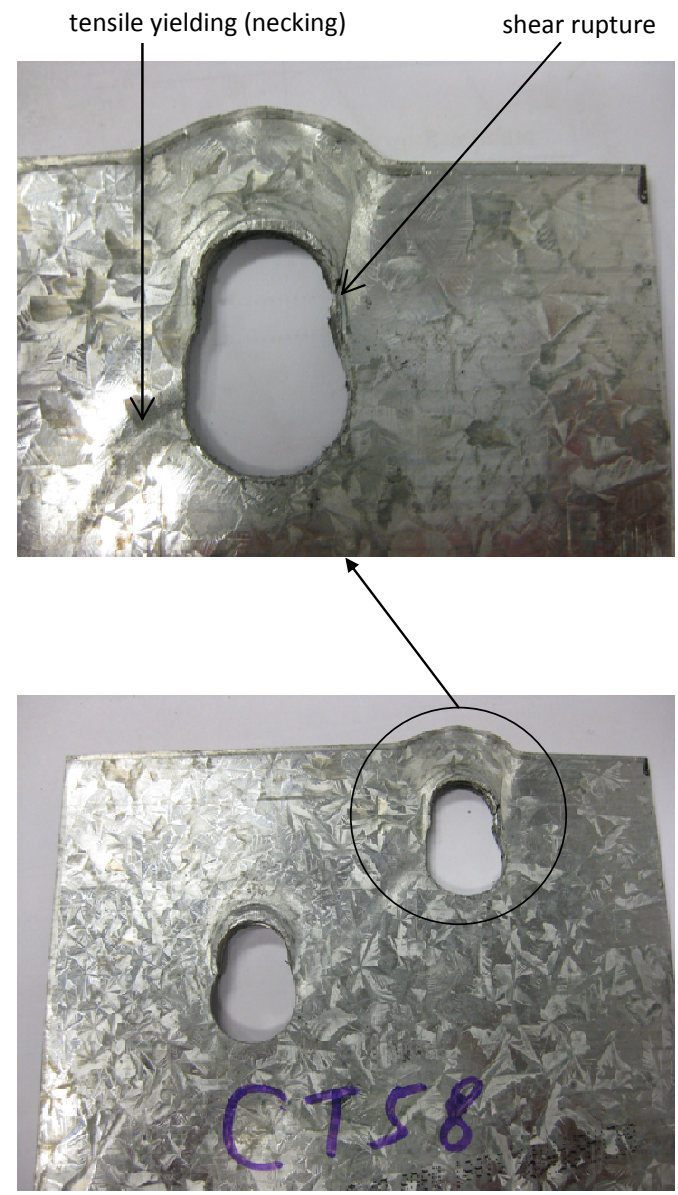

Figure 5 Shear rupture and tensile yielding

\subsection{Split block shear failure}

Four specimens were tested in order to investigate the accuracy of Equation (4) in determining the split block shear capacities of bolted connections in cold-reduced steel sheet with low material ductility and minimal strain hardening capability. All of them were $120 \mathrm{~mm}$ wide, with a single row of two unstaggered bolts. Table 3 lists the relevant geometric dimensions and the ratios of the ultimate test load $P_{\mathrm{t}}$ to the split block shear capacity $P_{\mathrm{sp}}$ predicted by Equation (4). 
All the specimens in Table 3 failed in split block shear through the shear yielding and tensile rupture mechanism, as shown in Figure 6 for specimen CPD32. It should be noted that the shear rupture at the left bolt hole only took place after the load was redistributed away from the fractured net sections, and was therefore not part of the split block shear failure mechanism.

It can be seen from Table 3 that Equation (4) can be used reliably to determine the capacities of the specimens failing in split block shear.

\section{Conclusions}

For the first time, it has been demonstrated through laboratory tests that a block shear failure by the shear rupture and tensile yielding mechanism is possible for staggered bolted connections, albeit for a particular configuration only. The test results, however, confirm that the dominant mechanism for block shear failures of staggered bolted connections is the shear yielding and tensile rupture mechanism.

Potential misidentifications for the simultaneous shear and tensile rupture mechanism of two specimens undergoing the shear yielding and tensile rupture mechanism have also been described. In the first instance, rupture at the downstream edge was due to the normal stresses acting transverse to the direction of loading, not due to the shear stresses. In both instances, tensile failure along the net sections took place first.

The equation derived by combining the block shear equation for unstaggered bolted connections and the net section tension equation for staggered bolted connections was found to be accurate for determining the block shear capacities of staggered bolted connection specimens in coldreduced steel sheets having low material ductility and minimal strain hardening capability. 
With a simple modification, the split block shear capacity can be determined with reasonable accuracy using the equation previously proposed by the first author.

\section{Acknowledgments}

This research project was funded by the Bluescope Steel Metallurgy Centre at the University of Wollongong. The specimens were fabricated by Ritchie McLean.

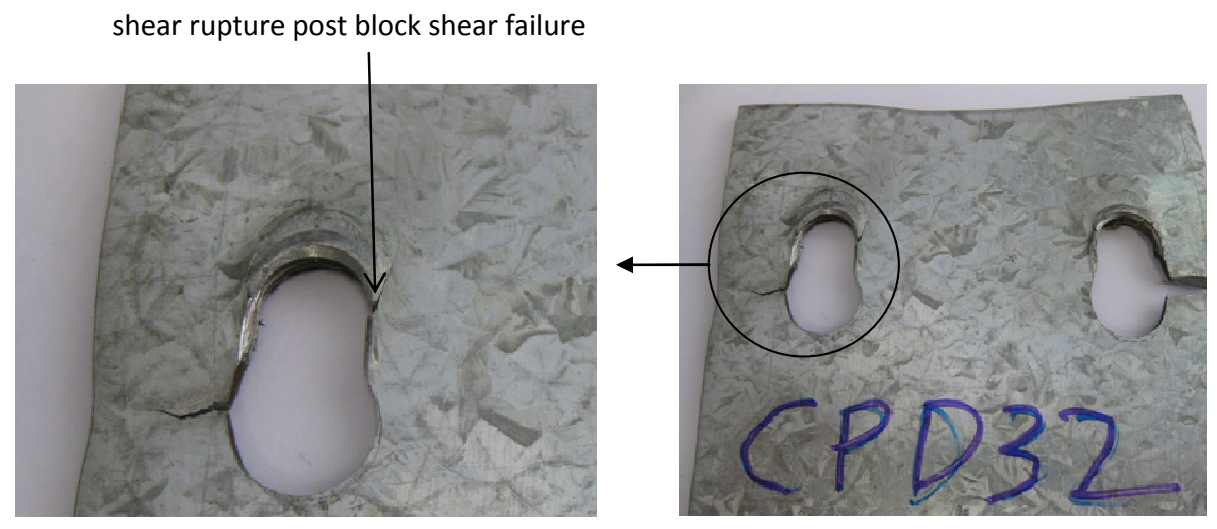

Figure 6 Split block shear failure

\section{References}

[1] Teh LH, Clements DDA. Block shear capacity of bolted connections in cold-reduced steel sheets. J Struct Eng 2012; 138 (4): 459-467.

[2] Hardash SG, Bjorhovde R. New design criteria for gusset plates in tension. Engineering Journal AISC 1985; 22 (2): 77-94.

[3] Huns BBS, Grondin GY, Driver RG. Tension and shear block failure of bolted gusset plates. Can J Civil Eng 2006; 33: 395-408. 
[4] Seleim S, LaBoube RA. Behavior of low ductility steels in cold-formed steel connections. Thin-Walled Struct 1996; 25 (2): 135-150.

[5] Teh LH, Clements DDA. Tension capacity of staggered bolted connections in cold-reduced steel sheets. J Struct Eng 2012; 138 (6): 769-776.

[6] Teh LH, Yazici V. Shear lag and eccentricity effects of bolted connections in cold-formed steel sections. Eng Struct 2013; 52: 536-544.

[7] Rosenstrauch PL, Sanayei M, Brenner BR. Capacity analysis of gusset plate connections using Whitmore, block shear, global section shear, and finite element models. Eng Struct 2013; 48: 543-557.

[8] Topkaya, C. Block shear failure of gusset plates with welded connections. Eng Struct 2007; 29 (1): 11-20.

[9] Ling TW, Zhao XL, Al-Mahaidi R, Packer JA. Investigation of block shear tear-out failure in gusset-plate welded connections in structural steel hollow sections and very high strength tubes. Eng Struct 2007; 29 (4): 469-482.

[10] Clements DDA, Teh LH. Active shear planes of bolted connections failing in block shear. J Struct Eng 2013; 139 (3): 320-327.

[11] Teh LH, Gilbert BP. Net section tension capacity of bolted connections in cold-reduced steel sheets. J Struct Eng 2012; 138 (3): 337-344.

[12] Teh LH, Hancock GJ. Strength of welded connections in G450 sheet steels. J Struct Eng 2005; 131 (9): 1561-1569.

[13] Cunningham TJ, Orbison JG, Ziemian RD. Assessment of American block shear load capacity predictions. J Construct Steel Res 1995, 35 (3): 323-338. 
[14] Kim TS, Kuwamura H, Kim SH, Lee YT, Cho TJ. Investigation on ultimate strength of thinwalled steel single shear bolted connections with two bolts using finite element analysis. Thin-Walled Struct 2009; 47: 1191-1202. 